\title{
Exploratory Research Antimalarial Properties Alstonia Congensis - the Pilot Survey Results Conducted in Kenge, Province Kwango DRC
}

\author{
Albert Omega Mvunzi Ilunga ${ }^{1,2 *}$ and Willy Mvunzi Nketi ${ }^{1,3}$ \\ ${ }^{1}$ Assistant Higher Institute of Medical Techniques, Kenge, DRC \\ ${ }^{2}$ Academic Secretary General, Kenge, DRC
}

${ }^{3}$ Laboratory manager, Leprosy and Tuberculosis Provincial Coordination, Health Zone Kenge, DRC

*Corresponding author: Albert Omega Mvunzi Ilunga, Assistant Higher Institute of Medical Techniques, Kenge, DRC

\section{ARTICLE INFO}

Received: 幽 May 20, 2019

Published: May 31, 2019

Citation: Albert Omega Mvunzi I, Willy Mvunzi N. Exploratory Research Antimalarial Properties Alstonia Congensis - the Pilot Survey Results Conducted in Kenge, Province Kwango DRC. Biomed J Sci \& Tech Res 18(3)-2019. BJSTR. MS.ID.003167.

Keywords: Alstonia Congensis; Anti malaria; ASAQ; Malaria

\section{ABSTRACT}

Malaria is Ravaging tropical countries. This disease is the third leading causes of death worldwide with two to three million victims per year Mainly in Africa. Currently, traditional medical knowledge is increasingly used beens Among urban citoyens, Who wears modern medical and pharmaceutical care. This study is an exploratory survey on the use of Alstonia congensis in the treatment of malaria. The aim of this study is to compare the efficacy of the use of medicinal plants like Alstonia congensis versus a combination of artesunate and amodiaquine (ASAQ), as it is Commonly used at the secondary hospital of Kenge, The sample of this study Was heterogeneous, it Dealt with social Several layers of interviewed: teacher, Peasants and others, people of two, age groups, etc. All subjects selected Were positive for gold RTD test of thick blood. Results show That Alstonia but effective communities is use a decoction of Alstonia skin to Avoid the side effects Observed When Taking ASAQ. A comparison of the two treatments Reveals That 16 squares Were cured in the ASAQ group (40\%) versus 32 out of 40 patients $(80 \%)$ in the group congensis Alstonia. We Concluded That Alstonia contains a real antimalarial activity more than ASAQ.

\section{Summary}

Malaria ravaging tropical countries. This disease is the third leading cause of global mortality with two to three million victims per year mostly in Africa. Currently, the use of traditional medical knowledge is becoming even greater in urban residents who once resorted to medical care and modern pharmaceuticals.This study is an exploratory survey on the use of Alstonia congensis in the treatment of malaria. The main objective is to compare the efficacy of Alstonia congensis than the combination ASAQ (artesunate + amodiaquine) which is commonly used in high Kenge hospital to see if we need to encourage the use of plant. The sample for this study was heterogeneous, it is composed of several social strata (teachers, farmers and other the person of two of several age brackets etc.). All topics selected were positive TDR or thick blood. The population used the bark decoction of Alstonia to avoid the side effects seen when taking ASAQ and qu'Alstonia is effective. By comparing the two treatments, it was observed 16 cases healed from the group ASAQ (40\%) against 32 of 40 patients in the group of Alstonia congensis $(80 \%)$. We concluded qu'Alstonia contains a real anti malarial activity more ASAQ.

\section{Introduction}

Malaria is, in the last campaign Médecins Sans Frontières a weapon of mass destruction that nobody cares. The figures are frightening fact: we have between 700 million to 800 million malaria-affected people, 300 to 400 million clinical cases each year, and 2 to 3 million deaths annually, the majority are in sub-Saharan Africa. The fight against this disease is complicated by the fact that 
we recorded an increased resistance of vectors and parasites to molecules currently used Géneviève [1]. The proportion of deaths due to malaria in health facilities in DR Congo is estimated at 32, $5 \%$. Most modern antimalarial drugs used contain harmful side effects and are counterfeit Muamba [2]. Currently, the population of endemic areas of malaria uses the use of herbal remedies in the treatment of irritable bowel syndrome. The same is true in traditional Chinese herbal medicines that are commonly used in oriental countries.

Some clinical trials have shown the beneficial effects of herbal remedies in the symptomatic treatment of this disease $\mathrm{Mr}$ Plants [3]; Duraffourd et al. [4,5]; Burkill [6]. The World Health Organization recognizes the use of standardized extracts of Ginkgo leaves and Bakopa treat memory loss and concentration problems, fatigue and promotes mental performance Zhao Dong [7]; Mr Plant 2011; Niederhofer [8]; Lemmens [9]. The bark of the methanol extract of root Alstonia booneia antiplasmodial activity against Plasmodium berghei berghei Onwusonye et al. [10]. Lyon and Cline [11]. The Alstonia has various virtues: It treats diabetes, of epilepsy and asthma attacks, reduces hypertension and is an antimalarial. However, its therapeutic use seems little known in DR. Congo, while it is well known in India and elsewhere WHO [12]; David et al. [13]; Pauwels [14]. In DR Congo, the population of the Province of Kwango in general and that of the City of Kenge in particular is threatened by endemic malaria, and uses an herbal decoction, instead of modern antimalarial.

In view of the above, what is the opinion of the population of Kenge on the use of the bark decoction of Alstonia congensis? What drives are used in place of ASAQ (artesunate + amodiaquine)?Factors related to modern antimalarial would influence the use of Alstonia congensis in the management of malaria by the population of Kenge. From the outset, thea population of Kenge prefer more use of Alstonia congensis instead of modern antimalarial drugs. This preference would be motivated by the side effects associated with modern antimalarials. The main objective of this study is to compare the efficacy of Alstonia congensis than the combination ASAQ (artesunate + amodiaquine) to see whether to encourage the use of said plant in the treatment of malaria. Specifically, the study will seek to identify the characteristics of the respondents, collect their opinions on the use of decoction of Alstonia congensis identify motivators to use this decoction and make a comprehensive comparison of effectiveness between decoction of Alstonia and ASAQ. If actually the Alstonia congensis is effective in the cure of malaria, it should deepen its study to develop in the coming days to the Congolese population in general and Kwangolaise in particular, a malaria based on this plant in the modern form.

\section{Status Report}

Malaria treatment still pose serious difficulties. Several classes of products have successively emerged, each with its advantages and disadvantages, but the range of drugs remains narrow for the discovery of new malaria seems laborious after Ouattara was quoted by Nsimba [15]. Despite progress in malaria surveillance and treatment availability, some people worry that it will take to adopt "radical measures" to curb forms of malaria resistant to drugs and prevent that history has proven to be a intercontinental deadly spread (White, 2014). Antimalarial drug resistance is a real public health impact. Therefore Onwusonye et al. [10], approved the antimalarial properties Alstonia boonei. His study was conducted to evaluate the activity of the extract antiplasmodial Alstonia of methanol root bark on boonei Infection with Plasmodium berghei berghei chloroquine-sensitive mice to justify its use as an antimalarial remedy in Nigeria. The plant extract was screened for blood schizontocide activity against Plasmodium berghei infection sensitive to chloroquine in the mouse AWE and Poeke [16].

The schizontocide activity was monitored at stages early and established infection because of the adverse effects of modern antimalarial drugs and treatment failures they record De Jong [17]. Moreover, the persistence of parasites in the blood increases the risk of severe anemia and consequently the frequency of blood transfusions with all the risks that entails. Collectively, the resistors increase the level of malaria transmission, which raises the number of accesses and therefore the cost of consultations per patient Chudnoff [18]. The development of resistance of Plasmodium falciparum to amino-4-quinoléites and its rapid spread throughout the malarious areas of the world quickly revealed the need to consolidate the policies against malaria. The distribution of known resistance to other antimalarial drugs and decreased sensitivity to quinine has prompted the development of new molecules with antimalarial activity. The development of these antimalarial substances was based on extensive studies of traditional pharmacopoeia Fargiere et al. [19]. Experts from Public Health and scientists fear that the third wave of resistance to antimalarial history spreads in Asia and Africa if "radical measures" are not adopted quickly. Resistance has also been associated with the use of counterfeit drugs, poor quality or unregulated migration and unusual genetic structure of malaria parasites found in western Cambodia Elford [20]. At present, the resistance thresholds in several major antimalarials (quinine, amodiaquine, artemisinin, mefloquine, lumefantrine) remain undefined. Currently, the use of traditional medical knowledge is becoming even greater in urban residents who once resorted to medical care and modern pharmaceuticals Kakule [21]. While most studies praise the efficacy of quinine against severe malaria falciparum worldwide Mueller et al. 1997; Neuwinger [22] Study Nsimba et al. [15] reveals rather than injectable artesunate is better than quinine. If one is striving to recommendations of the World Health Organization can immediately say that the effectiveness of the injectable artemisinin would be higher than quinine in terms of the treatment of severe malaria WHO [23]; WHO and MSF, 1997. The pharmacological evaluation of traditional remedies should 
lead to recommendations for use, some plants are well known for their real antimalarial activity Fargiere et al. [19], Genevieve [1].

\section{Materials and Methods}

\section{Description of the Study Environment}

The study was conducted mainly in the city of Kenge, capital of the territory of Kenge in the province Kwango, Democratic Republic of Congo. This city is built on the left bank of the river Wamba. Mazaba is the name of the small source of swampy water that runs through the city in the sagittal plane, and flows into the river. The shores of this source and are richly forested Wamba Alstonia congensis species used by the population for its antimalarial properties and giant palms. The middle of the tropical climate encourages the growth of several species of mosquitoes transmitters of malaria. Pictures of the plant have been drawn using a canon digital camera to enable readers to get an overall idea of the plant.

\section{Description of the Plant and its Preparation}

There are several species Alstonia including Alistonia the Alstonia scholaris, Alstonia macrophyllaAlstonia boonei, Alstonia congensis ...). Of these varieties, the Alstonia congensis is the only variety used by the population of Kenge (Figure 1). The plant has an average size of up to $15-25 \mathrm{~m}$ in height. Its bark is smooth or rough. The inner part of the bark is creamy, with abundant latex white as curd. Its top is stepped. The Alstonia congensis (species found in DR Congo), is usually found in swampy areas up to $500 \mathrm{~m}$. It is also found sometimes on dry rocky soils. His fheets are arranged in whorls of 4-6 or 8, simple and entire, without stipules. Its stalk reaches 0.5 to $1 \mathrm{~cm}$ long. It is flattened and grooved above, with narrow triangular colleters at the base. Its limb $8-26 \mathrm{~cm} \times 3.5$ to $11.5 \mathrm{~cm}$ is obovate to spatulate, base cuneate to rounded to shortly acuminate at apex, sometimes retuse, leathery, glabrous, with many ribs, lateral ribs joining close to the edge.
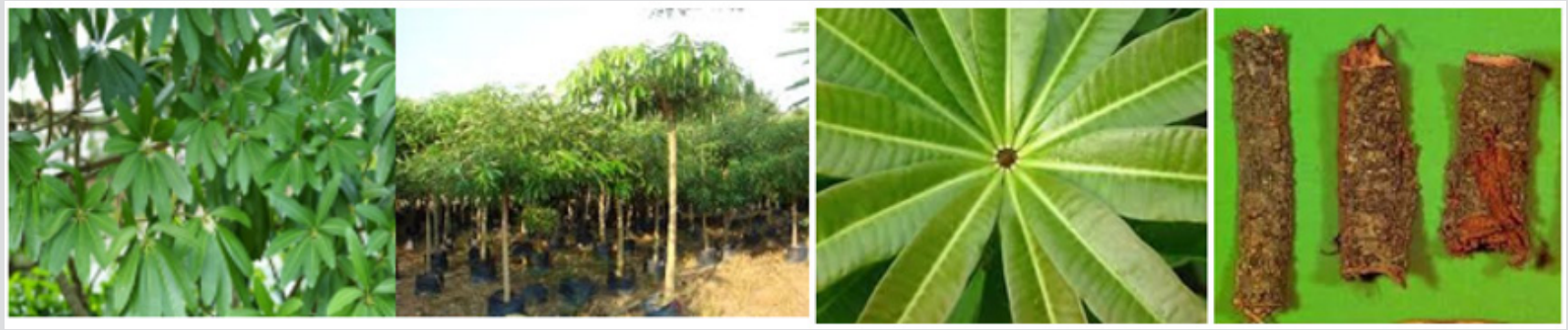

Figure 1: Especes Alstonia congensis found in Kwango, DR Congo (Authors, 2018).

Its inflorescence cyme terminal umbel composed of up to 25 cm long; peduncle 3.5-12 cm long, thick; scaled up to $2 \mathrm{~mm}$ long Raponda-Walker and Sillans [24]. The flowers are bisexual, regular, 5 mothers, fragrant; pedicel 3-5 or even $9 \mathrm{~mm}$ long; sepals up to 3 $\mathrm{mm}$ long, fused at base, smooth but slightly hairy on their edges; colored corolla cream, pale yellow or pale pink, pubescent, tube 4-7.5 mm long, widening near the end, obliquely obovate lobes, 4-10 mm long; stamens inserted on the upper part of the corolla tube, filaments about $0.5 \mathrm{~mm}$ long, anthers up to $1.5 \mathrm{~mm}$ long; ovary superior, ovoid, glabrous or sometimes slightly pubescent, style 1-3.5 mm long, ending in a pistil composed of a basal ring head, a cylindrical central portion and an apex portion and elongated stigmoid slotted Ebanyenle et al. [25]. Sidiyasa [26].

\section{Preparation of the Decoction}

The removal of bark Alstonia congensis is performed using a machete. After this deduction, bark are immediately exposed to the sun to allow drying latex. Then, they are cut into pieces and placed in the pot containing from 2 to 3 liter of water. These barks are boiled up to obtain at least one liter of decoction which is taken because of half a glass two to three doses per day, for four to five days Neuwinger [22].

\section{Sampling and Techniques Data Collection}

\section{Methodological Approach}

For sampling, 80 positive subjects Rapid Diagnostic Test $(\mathrm{RDT}+)$ was taken in a population who have used the decoction of Alstonia congensis and modern antimalarial drugs. Two groups were formed: one consisting of patients treated with the combination ASAQ and one patient treated with the decoction of Alstonia congensis. Qualitative analysis of data was to compare the efficacy of Alstonia congensis than the combination ASAQ (artesunate and amodiaquine) which is the main anti-malarial used $(72.5 \%)$ in secondary hospital Kenge Boko in the health area.

\section{Selection Criteria, Inclusion and Exclusion}

The selection took into account the following criteria be resident of the capital of the Territory of Kenge, have been diagnosed positive TDR and being treated with modern and traditional antimalarial. Were included in the study 80 subjects of both sexes with a positive diagnosis of malaria, who usedalready used the decoction of Alstonia congensis and modern antimalarial drugs. Subjects who do not meet the above criteria will were excluded from the study. 


\section{Data Analysis Techniques}

The analyzes were mainly based on descriptive statistics and qualitative analysis. The qualitative methodology was based primarily on the analysis of patterns. The evaluation was made from the comparison research question previous studies of modern and traditional antimalarials. Quinine, artesunate and combination Artesunate / amodiaquine (ASAQ) are the main antis malaria the most used by the population because of their virtues antis malarial recognized. (Table 1) summarizes these antis malaria that were most used in 2017.

Table 1: Rates of use of modern malaria antis in 2017.

\begin{tabular}{|c|c|c|}
\hline Pharmaceuticals & Use rate & Percentage \\
\hline Quinine & 50 & 8.06 \\
\hline Artesunate & 120 & 19.35 \\
\hline ASAQ (artesunate and amodiaquine) & 450 & 72.58 \\
\hline Total & 620 & 99.99 \\
\hline
\end{tabular}

Source : Register of patients (Secondary Hospital Kenge, 2017)

Descriptive statistics mainly consisted in the calculation of frequencies and simple differences. The calculation of the frequencies was based on the following equation (Equation 1):

$$
f=\frac{F O}{F A} * 100
$$

[Equation 1]

Or,

Relative frequency $\mathrm{f}=$

$\mathrm{FO}=$ Observed frequency

$\mathrm{FA}=$ expected frequency

The calculation of simple differences was made based on the following equation (Equation 2):

$$
D=E_{j}-O_{i} \quad[\text { Equation 2] }
$$

Où,

Ei, the expected strength of thusers Alstonia congensis

Oj, effective jth observed in theuse of modern antimalarial

the data collected were analyzed using computer software MS Excel 2010 and SPSS 17.0. These results were presented in the form of frequency tables and graphs.

\section{Analysis Results}

\section{Profile of Respondents}

The men were more numerous in this study was $62 \%$ against $38 \%$ of women (Figure 2). Subjects were age confused with a predominance observed in the range of 42 years and over (Figure $3)$. The subjects selected were either without instruction or the primary, secondary and tertiary levels (Figure 4). There was a predominance of Yaka ethnic group in the use of Alstonia congensis (75\%), followed by Mbala (17\%) and Yansi (8\%) (Figure 5). Finally,
Alstonia is operated by all social strata including farmers, teachers and other (Figure 6).

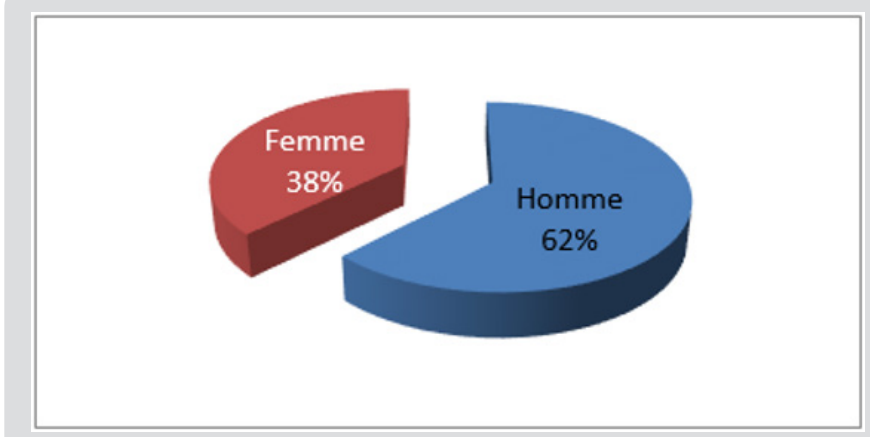

Figure 2: Distribution of users and non-users of Alstonia sex (Authors, 2018).

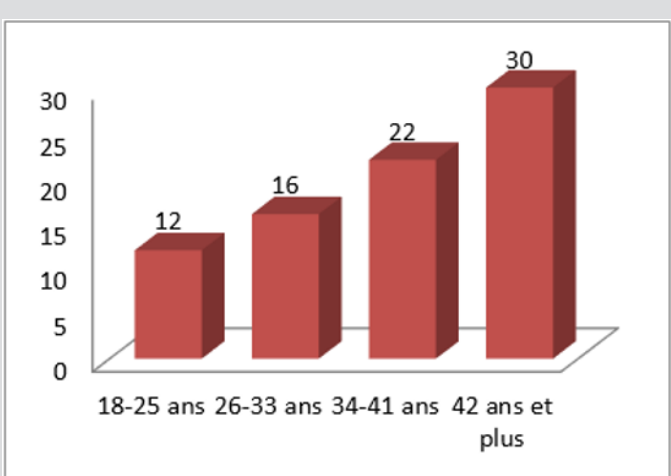

Figure 3: Distribution of respondents by age (Authors, 2018).

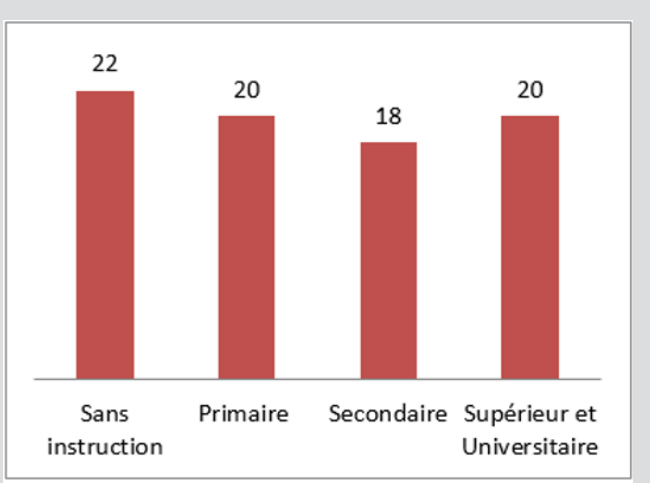

Figure 4: Distribution of respondents by level of education (Authors, 2018).

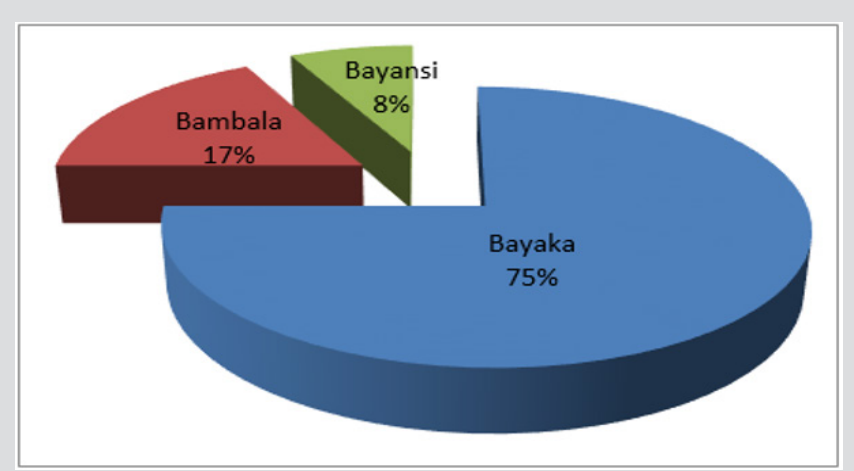

Figure 5: Ethnic affiliation of respondents (Authors, 2018). 


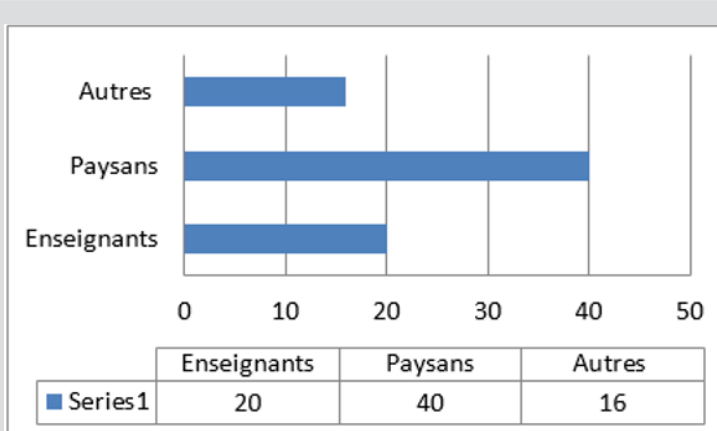

Figure 6: Distribution of the surveyed by strata (Authors, 2018).

\section{Perception of Antimalarial Properties Alstonia Congen- sis of Respondents}

To the question "What motivates you to use Alstonia congensis" all respondents answered "it costs nothing" (100\%), "no adverse effects" (100\%) and effective against malaria (100\%) (Table 2). When asked "why not use modern antimalarials? "The 40 users Alstonia congensis, 20, confessed to have avoided the adverse effects of modern antimalarial, 5 returned on forfeits inefficiency and 15 products due to lack of means (Figure 7). Parasitemia group Alstonia congensis was characterized by a TDR positive up to $77.5 \%$ of cases, followed by the drop positive thick (GE +) $22.5 \%$ of cases. From the group ASAQ it was recorded parasitaemia 67.5 to the positive TDR (TDR +) and $20 \%$ for a positive thick goute (GE +) (Table 3). Based on the thermal evolution in patients treated with the combination ASAQ it was found a resolution of fever on the first day in $15 \%$ of cases, $7.5 \%$ in the second day, $15 \%$ on day $2,5 \%$ on the fourth day 0 and the rest of the day.

Table 2: Virtues of malaria Alstonia congensis approached by respondents.

\begin{tabular}{|c|c|c|c|}
\hline \multirow{2}{*}{ Pattern of use } & \multicolumn{2}{|c|}{ Numbers } & \% \\
\cline { 2 - 4 } & FA & FO & \\
\hline Effective against malaria & 40 & 40 & \\
\hline No side effects & 40 & 40 & 100 \\
\hline Does not cost anything & 40 & 40 & 100 \\
\hline
\end{tabular}

Source : Authors (2018).

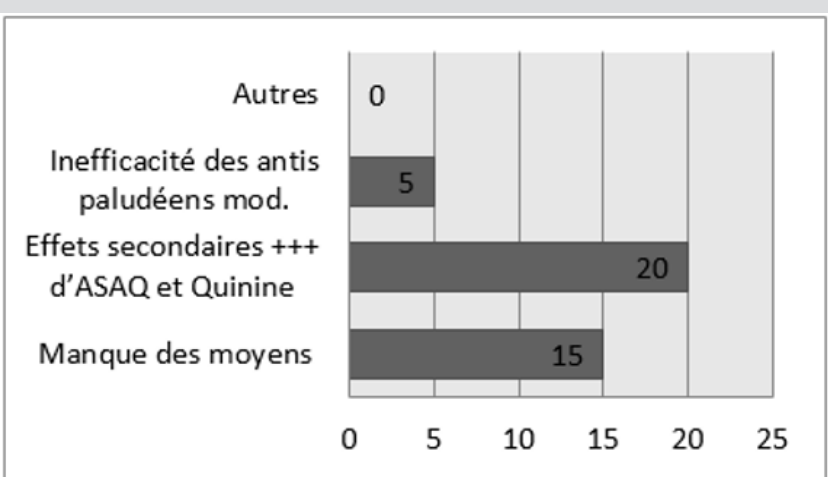

Figure 7: Motivation of respondents to use Alstonia congensis (Authors, 2018).
Table 3: Control parasitaemic.

\begin{tabular}{|c|c|c|c|c|}
\hline \multirow{2}{*}{$\begin{array}{c}\text { Examinations } \\
\text { carried }\end{array}$} & \multicolumn{2}{|c|}{ ASAQ } & \multicolumn{2}{c|}{ Alstonia } \\
\cline { 2 - 5 } & Frequency & $\begin{array}{c}\text { Percent } \\
\text { (\%) }\end{array}$ & Frequency & $\begin{array}{c}\text { Percent } \\
\text { (\%) }\end{array}$ \\
\hline TDR + & 30 & 75 & 31 & 77.5 \\
\hline TDR- & 0 & 0 & 0 & 0 \\
\hline GE + & 10 & 25 & 9 & 22.5 \\
\hline gE- & 0 & 0 & 0 & 0 \\
\hline Total & 40 & 100 & 40 & 100 \\
\hline
\end{tabular}

Source : Authors (2018).

In the group of patients treated with Alstonia congensis, it was observed a disappearance of fever on the first day of taking the morning and evening decoction up to $25 \%$ of cases, $30 \%$ the second day, $15 \%$ third day and $10 \%$ on the fifth day after dosing. (Tables 4 \& 5) shows that the unwanted side effects are mainly observed in the group of patients treated with the combination of ASAQ (artesunate + amodiaquine) or 100\% have experienced nausea and vomiting; $90 \%$ for general malaise; $87.5 \%$ had headache; $75 \%$ had palpitations; $62.5 \%$ of the stomach cramps. $45 \%$ had diarrhea, $22.5 \%$ had bloated to heat and sweating, finally, $22.5 \%$ felt dizziness. In the group of Alstonia congensis two side effects were observed: nausea in 1 patient $(2.5 \%)$ and diarrhea 1 patient (2.5\%). (Table 6) Based on the evolution of the treatment, 16 cases from the group ASAQ, (40\%) are cured against 32 patients in the group of Alstonia congensis, (80\%). It was recorded 14 cases of discontinuation of treatment (35\%) from the group ASAQ against 5 cases (12.5) from the group of Alstonia congensis. Medication change was observed more in the group of ASAQ (25\%) against 12.5\% in the group of patients who took Alstonia congensis.

Table 4: Evolution therapy (fever) in both treatments.

\begin{tabular}{|c|c|c|c|c|}
\hline \multirow{2}{*}{$\begin{array}{c}\text { Fever } \\
\text { disappearance }\end{array}$} & \multicolumn{2}{|c|}{ ASAQ } & \multicolumn{2}{c|}{ Alstonia } \\
\cline { 2 - 5 } & Frequency & Percentage & Frequency & Percentage \\
\hline On the first day & 6 & 15 & 10 & 25 \\
\hline On day & 3 & 7.5 & 12 & 30 \\
\hline On the third day & 6 & 15 & 6 & 15 \\
\hline On the fourth day & 1 & 2.5 & 0 & 0 \\
\hline On the fifth day & 0 & 0 & 4 & 10 \\
\hline On the sixth day & 0 & 0 & 0 & 0 \\
\hline On the seventh day & 0 & 0 & 0 & 0 \\
\hline Total & 16 & 40 & 32 & 80 \\
\hline
\end{tabular}

Source : Authors (2018).

Table 5: Evolution therapy (fever) in both treatments.

\begin{tabular}{|c|c|c|c|c|}
\hline \multirow{2}{*}{ Side effects } & \multicolumn{2}{|c|}{ ASAQ } & \multicolumn{2}{c|}{ Alstonia } \\
\cline { 2 - 5 } & Frequency & Percentage & Frequency & Percentage \\
\hline $\begin{array}{c}\text { Hot flashes and } \\
\text { sweating }\end{array}$ & 9 & 22.5 & 0 & 0 \\
\hline palpitations & 30 & 75 & 0 & 0 \\
\hline abdominal cramps & 25 & 62.5 & 0 & 0 \\
\hline $\begin{array}{c}\text { Nausea and } \\
\text { vomiting }\end{array}$ & 40 & 100 & 1 & 2.5 \\
\hline
\end{tabular}




\begin{tabular}{|c|c|c|c|c|}
\hline $\begin{array}{c}\text { Generalized } \\
\text { malaise }\end{array}$ & 36 & 90 & 0 & 0 \\
\hline Diarrhea & 18 & 45 & 1 & 2.5 \\
\hline Dizziness & 9 & 22.5 & 0 & 0 \\
\hline Headaches & 35 & 87.5 & 0 & 0 \\
\hline
\end{tabular}

Source : Authors (2018).

Table 6: Final Evaluation of treatment in both products.

\begin{tabular}{|c|c|c|c|c|}
\hline \multirow{2}{*}{$\begin{array}{c}\text { Fever } \\
\text { disappearance }\end{array}$} & \multicolumn{2}{|c|}{ ASAQ } & \multicolumn{2}{c|}{ Alstonia } \\
\cline { 2 - 5 } & Frequency & $\begin{array}{c}\text { Percent } \\
(\%)\end{array}$ & Frequency & $\begin{array}{c}\text { Percent } \\
\text { (\%) }\end{array}$ \\
\hline Healing & 16 & 40 & 32 & 76.2 \\
\hline $\begin{array}{c}\text { Discontinuation of } \\
\text { treatment }\end{array}$ & 14 & 35 & 5 & 11.9 \\
\hline Transferred & 6 & 15 & 0 & 0 \\
\hline $\begin{array}{c}\text { Changing } \\
\text { treatment }\end{array}$ & 4 & 10 & 5 & 11.9 \\
\hline Total & 40 & 100 & 42 & 100 \\
\hline
\end{tabular}

Source : Authors (2018).

\section{Discussion of Results}

\section{Discussion on the Profile of the Respondents}

Observing the heterogeneous character of the sample, it seems that the various layers of the rural population is involved in the fight against malaria by exploiting antimalarial virtues of Alstonia congensis. This especially since both sexes, different age groups, the combined intellectual levels, and the three ethnic groups that make up the population make use of Alstonia congensis. The men were more numerous in this study was $62 \%$ against $38 \%$ of women (Figure 2). The subjects were confused age with a prevalence observed in the range of 42 years and over (75\%) (Figure 3). The subjects selected were either without instruction or the primary, secondary and tertiary levels (Figure 4). There was a predominance of Yaka ethnic group (75\%) more user Alstonia congensis (75\%).

\section{Discussion of the use and the Choice of Alstonia Congensis}

To the question "What motivates you to use Alstonia congensis? "All respondents answered" it costs nothing "(100\%)," no adverse effects "(100\%) and effective against malaria (100\%) (Table 1). Of the 40 users Alstonia congensis, 20, confessed to have avoided the adverse effects of modern antimalarial, 5 returned to the ineffectiveness of such products, and 15 due to lack of means to procure modern malarial antis. ATCurrently, the malaria resistance thresholds in several major antimalarials (quinine, amodiaquine, artemisinin, mefloquine, lumefantrine) still remain to be defined. The WHO recommendations (2014) on the introduction of injectable artesunate molecule in the first line treatment of severe malaria instead of quinine seems promising Nsimba et al. [15]. Despite this, the treatment of malaria still poses serious difficulties. Several classes of products have successively emerged, each with its advantages and disadvantages, but the range of drugs remains narrow for the discovery of new malaria seems laborious Ouattara [27]. These statements reflect the doubts and limitations that there with modern antimalarials. If all of these modern antimalarials are well considered, it is undoubtedly because of their side effects and resistance of Plasmodium to them. Under these conditions, the uses of the population with the use of Alstonia congensis is a necessity because it is considered as containing fewer side effects by users.

\section{Discussion on the Control Parasitaemic}

It is observed that in the group of Alstonia congensis parasitaemia was characterized by a TDR positive up to $77.5 \%$ of cases, followed by the positive thick Drop (GE +) (22.5\% of). The negative results of these two examinations (GE and negative TDR) represented only 0 cases. From the group ASAQ it was recorded parasitaemia 67.5 to the positive TDR (TDR +) and 20\% for a positive thick goute $(\mathrm{GE}+)$. That said, all selected subjects were positive for malaria in any examination.

\section{Discussion on Etherapeutic Evolution of Fever During Processing}

Thus, thermal evolution in patients treated with the combination ASAQ, it was found a resolution of fever on the first day in $15 \%$ of cases, $7.5 \%$ in the second day, $15 \%$ on day $2,5 \%$ on the fourth day 0 and the rest of the day. In the group of patients treated with Alstonia congensis, it was observed a disappearance of fever on the first day of taking the morning and evening decoction up to $25 \%$ of cases, $30 \%$ the second day, $15 \%$ third day and $10 \%$ on the fifth day after dosing. The assessment of the duration of the temperature drop is one of the most important parameters to be considered for detecting the time required for a therapeutic response of the molecule. The study by Fargiere et al. [19] cited by Nsimba et al. [15] on the trial of artemether and quinine in the treatment of severe falciparum malaria in adults and older children in Cameroon has identified the average time for negativity of parasitaemia between 16 and 64 hours (with a confidence interval $34.6 \pm 9.6$ ) in artemether and between 24 and 64 hours (with a confidence interval of $42.4 \pm 9.7)$ as quinine. The study noted a significant gain of 7.8 hours $(p=0.0004)$ in patients receiving artemether.

Moreover, Ndimubanzu (2003) in his study on the efficacy of artemether versus that of quinine in the treatment of severe malaria in children in Rwanda, found that after 38 hours (with an interval of trusted $12.24 \pm 63.76$ ), $50 \%$ of patients taking artemether no longer have fever. For patients taking quinine this proportion is reached at the $48^{\text {th }}$ hour (with a confidence interval $37.26 \pm 58.74$ ). Results slightly lower than those found in this study. However, observing closely the different results, there must be concluded qu'Alstonia congensis would be much faster than ASAQ so that within 24 hours already, Antimalarial properties of Alstonia are fascinating. A study showed qu'Alstonia was commonly used for years against malaria fevers. Its mechanism of action is probably very different from those proposed for other classes of antimalarials Elford et al. [20]. 
The experimental study conducted by an NGO, ANAMED approved effective care based on plant Mueller et al. [28].

For its part, Khyade et al. [29] had demonstrated qu'Alstonia scholaris and Alstonia macrophylla are both rich in various types of bioactive alkaloids and contain a broad spectrum of biological and pharmacological activity in vitro and in vivo. This could be for Alstonia congensis future AWE et al. [16]. It is noteworthy that the decoction of Alstonia contains an active anti pyretic confirmed with further study because, among patients treated Rare were those who associated anti pyretic. In a study conducted by Onwusonye et al. [10], the results showed activity schizontocide blood decoction Alstonia bonnei, dose dependent at all stages of malaria infection. It was also observed that when the extract dose increased from 400 to $800 \mathrm{mg} / \mathrm{kg} /$ day, the activity suppressive chemo extract increased from $62.2 \%$ to $79.5 \%$. There was also an increase from $58.8 \%$ to $72.2 \%$ and from $66.4 \%$ to $82.9 \%$ for the storage and processing activities respectively. The schizontocidales activities observed were however comparable to those observed with the standard drug (chloroquine phosphate). It is therefore logical qu'Alstonia has an anti-malarial and anti-pyretic effect.

\section{Discussion of Side Effects Observed During Treatment}

Adverse side effects were observed in the group of patients treated with the combination of ASAQ (artesunate + amodiaquine). $100 \%$ felt nausea and vomiting; $90 \%$ of the general malaise. $87 \%$ had headaches; $75 \%$ and $62 \%$ palpitations the stomach cramps. $45 \%$ had diarrhea and $22 \%$ have experienced dizziness. WHO and MSF (1997) recognize that modern antimalarial result in various side effects, among others: tinnitus, headache, blurred vision, decreased hearing, nausea and diarrhea, pruritus, urticaria or rash, subcutaneous bleeding or under-mucosa and edema of the eyelids, mucous membranes and lungs etc. while overdose causes even disturbing effects. In the group of Alstonia congensis two minor side effects were observed: nausea to 1 in 40 (2.5\%) and diarrhea 1 of 40 patients (2.5\%). The study by Nsimba et al. [15] found that arthesunate would be a drug of first choice in the treatment of malaria. She mentions a death rate $7.9 \%$ in the group of children treated with quinine against $1.1 \%$ in the group of those treated with artesunate. The cure rate observed was $88.9 \%$ in the group of artesunate against $83.7 \%$ in the group of quinine. By cons, this study is exploratory and no users had reported treatment failure Alstonia congensis, it remains to see if really it is an observable location, lack of treatment failure Nsimba et al. [15]. Mayingila [30-32].

\section{Discussion on eASAQ Final Evaluation of Products and}

\section{Alstonia Congensis}

Thusof the course of treatment, 16 cases from the group ASAQ (40\%) are cured against 32 patients in the group of Alstonia congensis, (80\%). It was recorded 14 cases of discontinuation of treatment (35\%) from the group ASAQ against 5 cases (12.5) from the group of Alstonia congensis. Medication change was observed more in the group of ASAQ (25\%) against $12.5 \%$ in the group of patients who took Alstonia congensis.

\section{Conclusion and Recommendations}

\section{Conclusion}

In conclusion, Alstonia bark decoction of congensis has properties both antispasmodic and malaria. In doing based remedies Alstonia congensis are promising in the treatment of malaria. However, it is too early to recommend its routine use in the treatment of malaria. This plant should be evaluated through well planned testing and more widely to produce solid evidence of its effectiveness. This is more so as the methodological quality of clinical trial that aims to assess the plant is not yet firm. However, some evidence suggests that small low-quality trials reporting positive results are more likely to be associated with an overestimation of the effect.

\section{Recommendations}

The effectiveness of Alstonia congensis in malaria treatment is proven. A more extensive study on a larger sample, not only to reconfirm its effectiveness but also to determine its real active principle, improving its pharmaceutical presentations to determine dosages for its best use. This will also prevent the abusive and uncontrolled exploitation of this species.Since the included trials reported no serious adverse events associated with the use of plant-based remedies, this plant requires additional research to encourage culture. We have not undertaken a comprehensive study to determine the composition and dosage forms suitable in the manufacture of an anti malarial base of the plant under consideration, yet we are willing to do so in the future if partners that we read in find of interest.

\section{Advisory Note}

Form of the combination artesunate + amodiaquine (ASAQ).

\section{Thanks}

We acknowledge all those who provided their valuable contributions to various levels drafting of this article, including the anonymous reviewers, secretaries and members of the editorial board of this special edition and its academic editor. We are particularly grateful to the Academic Secretary General of the "Higher Institute of Medical Technologies - Mary Queen of Peace Kenge (ISTM-MRP Kenge)" Prof. Dr. Cush Ngonzo Luwesi, through which basic information for the preparation of this publication was reached us.

\section{Author Contributions}

This research is part of our observations undertaken in the city of Kenge, Democratic Republic of Congo (DRC) during 2018, with the guidance of Prof. Dr. Cush Ngonzo Luwesi. The authors thank him very much for his respective contribution. 


\section{References}

1. Genevieve B (2004) Antimalarial traditional remedies: alternative treatments.

2. Muamba C (2017) Counterfeit medicines on the Congolese market: Oly Ilunga takes the alarm; Times.cd.

3. Mr Plants (2017) Herbal remedies for the treatment of irritable bowel syndrome.

4. Duraffourd C, Hervicourt L, Lapraz JC (1990) clinical herbalism Brief No. 3, rheumatic disorders, digestive disorders, $2^{\text {nd }}$ (edn.). Masson, Paris, France.

5. Duraffourd C, Hervicourt L, Lapraz JC (1988) clinical herbalism Brief No. 2, ENT and pulmonary disorders Broncho; childhood diseases, skin diseases, $2^{\text {nd }}($ edn.). Masson, Paris, France.

6. Burkill HM (1985) The Useful Plants of West Tropical Africa, 2nd Edition Royal Botanic Gardens, Kew, Richmond, United Kingdom.

7. Zhao MX, Dong ZH, Yu ZH, Xiao SY, Li YM (2012) Effects of Ginkgo biloba extract in Improving episodic memory of patients with mild cognitive impairment: a randomized controlled trial. Zhong Xi Yi Jie He Xue Bao Beijing, China.

8. Niederhofer H (2010) Ginkgo biloba Treating patients with attentiondeficit disorder. Phytother Res 24(1): 26-27.

9. Lemmens R (2005) Alstonia congensis Engl. In: Louppe D, Oteng Amoako AA, Brink M (Eds.), PROTA (Plant Resources of Tropical Africa / Plant Resources of Tropical Africa). Wageningen, Netherlands. Accessed December 20, 2017.

10. Onwusonye JC, AA Uwakwe (2014) The antiplasmodial activity of methanol extract of root bark Alstonia boonei against Plasmodium berghei berghei infection in mice.

11. Lyon MR, Cline JC, Totosy de Zepetnek J, Shan JJ, Pang P, et al. (2001) Effect of the herbal extract combination Panax quinquefolium and Ginkgo biloba is attention-deficit hyperactivity disorder: a pilot study. Psychiatry Neurosci 26(3): 221-228.

12. WHO (2003) Research methodology in the field of health, training manual methods of scientific research; Regional Office for the Western Pacific Manila, $2^{\text {nd }}$ (edn.)

13. David P, Dumenil G (2007) Ethnopharmacological approach of plants used in traditional medicine in Cambodia in the treatment of infectious diseases, fevers and malaria. Special Report: Cambodia. Khan Chamkar Morn, Phnom Penh, Cambodia.

14. Pauwels L (1993) Nzayilu N'ti: a guide to trees and shrubs in the area of Kinshasa Brazzaville. Scripta Botanica Belgica. Volume 4. National Botanic Garden of Belgium, Meise, Belgium pp. 495.

15. Nsimba P (2018) Effectiveness of injectable artesunate versus quinine in the treatment of severe malaria in children aged 0-59 months in Kenge, DRC, J. HES.

\section{ISSN: 2574-1241}

\section{DOI: 10.26717/BJSTR.2019.18.003167}

Albert Omega Mvunzi Ilunga. Biomed J Sci \& Tech Res

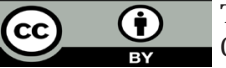

This work is licensed under Creative Commons Attribution 4.0 License

Submission Link: https://biomedres.us/submit-manuscript.php
16. Awe SO, Poeke OO (1990) Effect of Alstonia congensis is Plasmodium berghei berghei in mice. Fitoterapia 61(3): 225-229.

17. De Jong BHJ (1979) A revision of the African species Alstonia R.Br (Apocynaceae). Mededelingen Landbouwhogeschool Wageningen p: $1-16$.

18. Chudnoff M (1980) Tropical timbers of the world. USDA Forest Service, Agricultural Handbook No. 607, Washington DC, United States.

19. Fargiere JJ, Louis FJ, Duparcc S, Hounsinopu C, Ringwald OP, et al. (1999) Comparative trial of artemether and quinine in severe falciparum malaria in adults and older children in Cameroon. Tropical Medicine 59(2): 151-156.

20. Elford B, Mafumbi R, Phillipson J, Wilson R (1987) Potentiation of the antimalarial activity of qinghaosu by methoxylated flaVones, Transactions of the Royal Society of Tropical Medicine and Hygiene 81(3): 434-436.

21. Kakule C (2009) Knowledge, attitudes and community practices in the promotion of medicinal plants in the households of Afia Keshero health area in the DRC.

22. Neuwinger HD (2000) African traditional medicine: a dictionary of plant uses and applications. Medpharm Scientific, Stuttgart, Germany pp. 589

23. (2014) WHO, Support malaria, guide-training module involved in the fight against malaria. Geneva: World Health Organization.

24. Raponda Walker A, Sillans R (1961) The useful plants of Gabon. Paul Lechevalier Paris, France pp. 614.

25. Ebanyenle E, Oteng Amoako, A Baas P (2017) Alstonia conguensis

26. Sidiyasa K (1998) Taxonomy, phylogeny, and wood anatomy of Alstonia (Apocynaceae). Blumea Supplement 11. Rijksherbarium / Hortus Botanicus, Leiden University, Leiden, Netherlands pp. 1-230.

27. Ouattara B (2007) Support for cerebral malaria in children aged 0-15 years in Nianankoro Fomba hospital Segou (UFH / S). Doctoral thesis. Bamako: University of Bamako, Republic of Mali.

28. MS Mueller, Karhagomba IB, Hirt HM, Wemarkor E (2001) The potential of Artemisia annua L. as a remedy for malaria Produced locally in the tropics: agricultural, chemical and clinicals aspects. submitted for publication to Tropical Doctor 73(3): 487-493.

29. Khyade, MS, Kasote DM, Vaikos NP (2014) Alstonia scholaris (L.) R. Br. And Alstonia macrophylla Wall. ex G. Don: A comparative review is traditional uses, phytochemistry and pharmacology. J Ethnopharmacol 153(1): 1-18

30. Mayingila B (2017) Impact of artesunate in the treatment of malaria; Tfc, istm. Mary Queen of Peace Kenge.

31. Sauvain M (2002) From ethnopharmacology to laboratory results: difference does it mean irrelevance? Paris: IRD, France.

32. Mr Wilcox, Bodeker G, Rasoanaivo P (2004) Inside Wood. Accessed December 20, 2017.

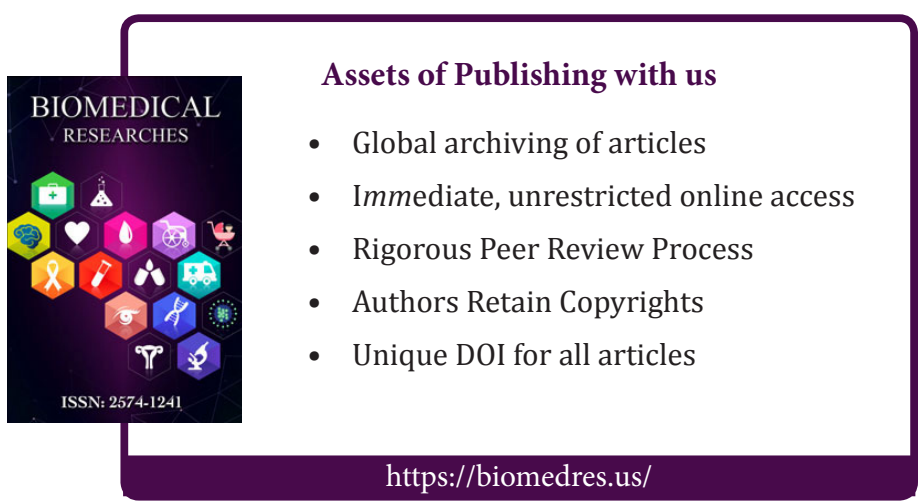

Copyright@ Albert Omega Mvunzi Ilunga | Biomed J Sci \& Tech Res| BJSTR. MS.ID.003167. 